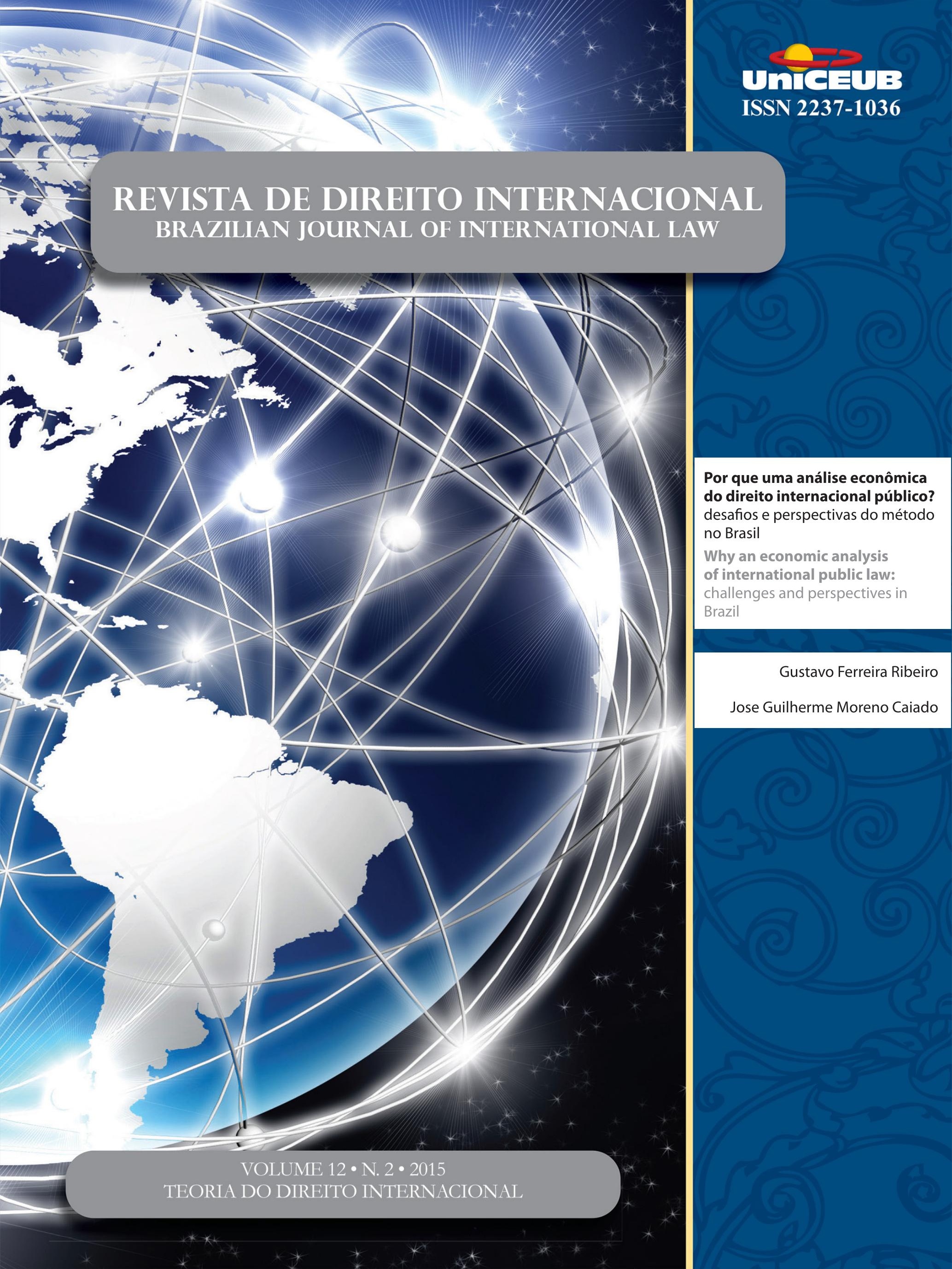




\section{Sumário}

CrôNiCAS DA ATUALIDADE do DiREITo INTERnACIONAL ..................................................... 2 Sarah Dayanna Lacerda Martins Lima, Carina Costa de Oliveira e Erika Braga

CrôniCas do Direito InternaCional dos InVESTIMENTOS ..............................................12 Nitish Monebhurrun

Por que voltar a Kelsen, o jurista do século XX ? 16 Inocêncio Mártires Coelho

O Princípio da Efetividade como conteúdo da norma fundamental (GrundNorm) DE KELSEN

Carlos Alberto Simões de Tomaz e Renata Mantovani de Lima

A JURIDIFICAÇÃo DE CONFLITOS POLÍTICOS NO DIREITO INTERNACIONAL PÚBLICO CONTEMPORÂ-

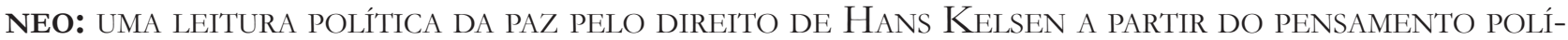
TICO De Claude Lefort

Arthur Roberto Capella Giannattasio

O SINCRETISMO TEÓRICO NA APROPRIAÇÃO DAS TEORIAS MONISTA E DUALISTA E SUA QUESTIONÁVEL UTILIDADE COMO CRITÉRIO PARA A CLASSIFICAÇÃO DO MODELO BRASILEIRO DE INCORPORA-

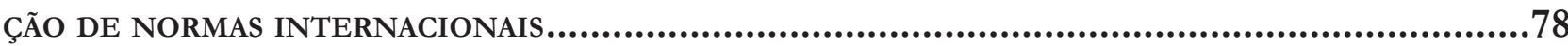
Breno Baía Magalhães

Direito Global em Pedaços: Fragmentação, Regimes e Pluralismo .98 Salem Hikmat Nasser

Por uma TeOria JURÍdica da INTEGRaÇão REgIONAL: A INTER-RELAÇÃO DiREITO INTERNO, DiREITO INTERNACIONAL PÚBLICO E DIREITO DA INTEGRAÇÃO Jamile Bergamaschine Mata Diz e Augusto Jaeger Júnior

A teOria DA INTERCONSTITUCIONALIDADE: UMA ANÁlISE COM BASE NA AMÉRICA LATINA...........160 Daniela Menengoti Ribeiro e Malu Romancini 
O DIÁLOGO HERMENÊUTICO E A PERGUNTA ADEQUADA À APLICAÇÃo DOS TRATADOS INTERNACIONAIS DE DIREITOS HUMANOS NO BRASIL: CAMINHOS PARA O PROCESSO DE INTERNACIONALIZAÇÃO

DA CONSTITUIÇÃO...................................................................................... 176

Rafael Fonseca Ferreira e Celine Barreto Anadon

O DIREITO COMPARADO NO STF: INTERNACIONALIZAÇÃO DA JURISDIÇÃO CONSTITUCIONAL BRASILEIRA

Carlos Bastide Horbach

THE PHILOSOPHY OF INTERNATIONAL LAW IN CONTEMPORARY SCHOLARSHIP: OVERCOMING NE-

GLIGENCE THROUGH THE GLOBAL EXPANSION OF HUMAN RIGHTS

Fabrício Bertini Pasquot Polido, Lucas Costa dos Anjos e Vinícius Machado Calixto

OpORTUNIDADES E DESAFIOS DAS TWAIL NO CONTEXTO LATINO-AMERICANO A PARTIR DE PERSPECTIVAS DOS POVOS INDÍGENAS AO DIREITO INTERNACIONAL

Fernanda Cristina de Oliveira Franco

Por Que uma ANÁlise ECONÔMICA Do DIREITO INTERNACIONAL PÚBLICO? DESAFIOS E PERSPECTIVAS DO MÉTODO NO BRASII

Gustavo Ferreira Ribeiro e Jose Guilherme Moreno Caiado

ANÁliSE ECONÔMICA do DIREITO INTERNACIONAL .263 Michele Alessandra Hastreiter e Luís Alexandre Carta Winter

RACIONALIDADE ECONÔMICA E OS ACORDOS BILATERAIS DE INVESTIMENTO 284 Michele Alessandra Hastreiter e Luís Alexandre Carta Winter

LOOKING FOR A BRICS PERSPECTIVE ON INTERNATIONAL LAW .304 Gabriel Webber Ziero

A INFLUÊNCIA DO DIREITO DESPORTIVO TRANSNACIONAL NO ORDENAMENTO JURÍDICO BRASILEIRO: DA REPRODUÇÃO DE NORMAS À APLICAÇÃO DIRETA PELA JURISDIÇÃO ESTATAL.......................3324 Tiago Silveira de Faria

CONVENCIONALIZAÇÃo DO DIREITO CIVIL: A APLICAÇÃo DOS TRATADOS E CONVENÇÕES INTERNACIONAIS NO ÂMBITO DAS RELAÇÕES PRIVADAS . 
NATIONAL JUdGES AND COURTS AS INSTITUTIONS FOR GLOBAL ECONOMIC GOVERNANCE 356

Juízes e tribunais nacionais como instituições para a governança global 356 Camilla Capucio

Is Trade Governance Changing? 371 Alberto do Amaral Júnior

OS FUNDOS ABUTRES: MEROS PARTICIPANTES DO CENÁRIO INTERNACIONAL OU SUJEITOS PERANTE O DIREITO INTERNACIONAL? 384

Guilherme Berger Schmitt

SHAREHOLDER AGREEMENTS IN PUBLICLY TRADED COMPANIES: A COMPARISON BETWEEN THE

U.S. AND BRAZIL. 402 Helena Masullo

REgulaÇÃo DO INVESTIMENTO ESTRANGEIRO DIRETO NO BRASIL: DA RESISTÊNCIA AOS TRATADOS BILATERAIS DE INVESTIMENTO À EMERGÊNCIA DE UM NOVO MODELO REGULATÓRIO 421 Fabio Morosini e Ely Caetano Xavier Júnior

DA QUALIFICAÇÃo JURÍDiCA dAS Distintas FORMAS DE PRESTAÇão TECNOLÓGICA: BREVE ANÁLISE DO MARCO REGULATÓRIO INTERNACIONAL

Daniel Amin Ferraz

REDEFINING TERRORISM: THE DANGER OF MISUNDERSTANDING THE MODERN WORLD'S GRAVEST THREAT

Jennifer Breedon

As EXECUÇões SELETIVAS E A RESPONSABILIZAÇÃo DE AGENTES TERRORISTAS 485 Alexandre Guerreiro

INTERNATIONAL CRIMINALS AND THEIR VIRTUAL CURRENCIES: THE NEED FOR AN INTERNATIONAL EFFORT IN REGULATING VIRTUAL CURRENCIES AND COMBATING CYBER CRIME Joy Marie Virga

Criminalidad transnacional organizada en el Ámbito del MERCOSUR: ¿Hacia un Derecho Penal Regional?. .528 Nicolás Santiago Cordini e Mariano Javier Hoet 
RUMO À INTERNACIONALIZAÇÃo DA PROTEÇÃO PENAL DO MEIO AMBIENTE: DOS ECOCRIMES AO ECOCÍDIO

Kathia Martin-Chenut, Laurent Neyret e Camila Perruso

Engaging the U.N. Guiding Principles on Business and Human Rights: the inter-AMERICAN COMMISSION ON HUMAN RIGHTS \& THE EXTRACTIVE SECTOR 571 Cindy S. Woods

O DIREITO HUMANO À COMUNICAÇÃo PRÉVIA E PORMENORIZADA DAS ACUSAÇÕES NOS PROCESSOS administrativos: O desprezo do Superior Tribunal de Justiça ao Pacto de San José da Costa Rica e À Corte Interamericana de Direitos Humanos .590

Daniel Wunder Hachem e Eloi Pethechust

A responsabilidade internacional do Brasil em FaCe do CONTRole de ConVENCionaliDADE EM SEDE DE DIREITOS HUMANOS: CONFLITO DE INTERPRETAÇÃO ENTRE A JURISDIÇÃO DA Corte Interamericana de Direitos Humanos e o Supremo Tribunal Federal quanto a LEI DE ANISTIA 612

Carla Ribeiro Volpini Silva e Bruno Wanderley Junior

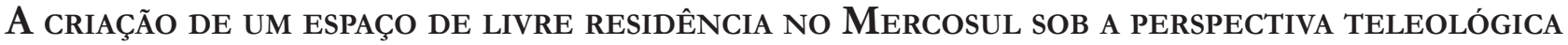
DA INTEGRAÇÃo REGIONAL: ASPECTOS NORMATIVOS E SOCIAIS DOS ACORDOS DE RESIDÊNCIA ....... 631

Aline Beltrame de Moura

A funcionalização como tendênCia evolutiva do Direito Internacional e sua conTRIBUIÇÃO AO REGIME LEGAL DO BANCO DE DADOS DE IDENTIFICAÇÃO DE PERFIL GENÉTICO NO BRASIL

Antonio Henrique Graciano Suxberger

O DIREITO INTERNACIONAL E A PROTEÇÃO DOS DIREITOS DE CRIANÇAS E DE ADOLESCENTES EM CONFLITO COM A LEI EM MOÇAMBIQUE

Bernardo Fernando Sicoche

ObTenÇão de PRovas no EXTERIOR: PARA ALÉM dA LEX FORI E LEX DiLigENTIAE. .685 André De Carvalho Ramos 
A Slight Revenge and a Growing Hope for Mauritius and the Chagossians: The UNClos Arbitral Tribunal's Award of 18 March 2015 on Chagos Marine Protected Area (Mauritius v. United Kingdom)

Géraldine Giraudeau

ANÁLISE DA RESPONSABILIDADE INTERNACIONAL DA UCRÂNIA POR VIOLAÇÃo DOS DIREITOS HUmanos na QUeda do voo da Malaysia Airlines (MH17). .728

Daniela Copetti Cravo

NatureZa JURÍdica do DESENVOLVIMENTO SUSTENTÁVEL No DIREITO INTERNACIONAL ........739 Pedro Ivo Diniz

A INFLUÊNCIA Da SOFT LAW NA FORMaÇão do DiREITo AMBIENTAL .767 Leonardo da Rocha de Souza e Margareth Anne Leister

As COMPLICADAS INTER-RELAÇÕES ENTRE OS SISTEMAS INTERNOS E INTERNACIONAIS DE PROTEÇãO DO DIREITO AO MEIO AMBIENTE SADIO. 785 José Adércio Leite Sampaio e Beatriz Souza Costa 


\title{
Por que uma análise econômica do direito internacional público? desafios e perspectivas do método no Brasil*
}

\author{
Why an economic analysis of international \\ public law: challenges and perspectives in \\ Brazil
}

\author{
Gustavo Ferreira Ribeiro** \\ Jose Guilherme Moreno Caiado***
}

\section{Resumo}

o objetivo deste artigo é esclarecer o método, desafios e perspectivas da análise econômica do direito internacional público (AEDIP) no Brasil. O método vem sendo utilizado nas academias norte-americana, de forma precursora, e europeia, mais recentemente. No Brasil, é diminuto o número de docentes, publicações e grupos de pesquisa nesse campo. Há naturalmente uma questão temporal (formação de massa crítica) para sua introdução, mas também barreiras de linguagem e compreensão de seus limites e possibilidades. Na essência, a AEDIP é uma transposição da consolidada análise econômica do direito doméstico, com adaptações, para o plano internacional. Ao se utilizar de uma abordagem interdisciplinar por meio de conceitos econômicos, como escassez e racionalidade, o método contribui para explicar o direito (positivo, "ser"), prescrever soluções (normativo, "dever-ser") e visualizar as potenciais consequências das interpretações das normas no mundo real (hermenêutica). Partindo de dois problemas selecionados acerca da origem material das fontes do direito internacional (tratados e costumes) e de duas áreas específicas (investimentos internacionais e direitos humanos), esclarecem-se neste artigo essas abordagens. Conclui-se pela indispensável visão proporcionada pela AEDIP como mais uma das luzes sobre a "catedral" do direito internacional, e a possibilidade de se superarem os obstáculos cognitivos do método.

Palavras-chave: Direito internacional público. Direito e economia. Análise econômica. Academia brasileira.

* Recebido em 16/11/2015

Aprovado em 08/12/2015

** Autor Convidado: Professor do Programa de Mestrado e Doutorado em Direito - UniCEUB, Brasília. E-mail: Gustavo.Ribeiro@uniceub.br

*** Autor Convidado: Doutorando do Institute of Law and Economics, Universidade de Hamburgo. E-mail: Jose.Caiado@ile-graduateschool.de

\section{Abstract}

This paper aims at clarifying the method, challenges and perspectives of the law and economics of public international law (LEPIL) in Brazil. The method has been used in the North American, at earliest, and in the European academy, more recently. In Brazil, the number of faculty, publications, and research groups in the area is meager. Naturally, there is a temporal issue over the formation of a critical mass to deal with the method, but also 
language and comprehension barriers about its possibilities and limits. In the essence, LEPIL is the transposition of the consolidated law and economics - as applied to domestic law - to the international realm, with adaptations. While using an interdisciplinary approach, drawing from economic concepts, such as scarcity and rationality, the method serves to explain international law (positive, "be"), prescribe solutions (normative, "should be"), and predict the consequences of interpretation in the real world (hermeneutics). By focusing in two selected problems about the material origin of sources of international law (treaties and customs) and two specific areas (international investments and human rights), this article clarifies these approaches. The paper concludes about the indispensable vision supplied by LEPIL, as one of lights on the "cathedral" of international law, and the possibility of overcoming its cognitive hurdles.

Keywords: Public international law. Law and economics. Economic analysis of law. Brazilian academy.

\section{INTRODUÇão}

Este $\operatorname{artigo~}^{1}$ oferece razões para que se desenvolvam, catedralmente, ${ }^{2}$ estudos e pesquisas por meio da análise econômica aplicada ao direito internacional público (AEDIP), sob uma perspectiva da academia brasileira. Inicialmente, explicam-se as particularidades da análise econômica do direito (AED), esclarecendo o que ela adiciona às discussões de direito internacional público (DIP). Como argumento central, vê-se o papel imprescindível da AEDIP como um olhar adicional para o jurista, auxiliando-o na compreensão do fenômeno jurídico internacional de forma amplificada.

\footnotetext{
1 Uma versão preliminar e sintética deste artigo foi apresentada no II Workshop do grupo de pesquisa Direito Global e suas Alternativas Metodológicas, em 2014, a ser publicada nos anais do evento (no prelo, 2016). A presente versão compreende um esforço dos autores de expandir e examinar mais detalhadamente conceitos centrais da disciplina, bem como sua aplicação a certas áreas de direito material. $2{ }^{4}$ Neologismo não tem, seguramente, qualquer conotação ecumênica, mas se inspira na célebre passagem de Calabresi e Melamed de se lançar uma visão adicional sobre um problema para que se tenha uma melhor compreensão do todo. E é, apenas, mais uma das visões possíveis. Veja-se CALABRESI, Guido; MELAMED, A. Douglas. Property rules, liability rules, and inalienability: one view of the cathedral. Harvard Law Review, v. 85, n. 6, p. 1089-1128, Abr. 1972. p. 1089-1090, nota de rodapé 2 .
}

Como panorama geral, embora existam pelo menos dezesseis grupos de pesquisa ${ }^{3}$ em AED no Brasil, a academia brasileira vem só recentemente incursionado na $\mathrm{AEDIP}^{4}$. Os poucos manuais ou coletâneas de AED escritos ou traduzidos para o vernáculo pouco auxiliaram nessa construção. ${ }^{5}$ Eles simplesmente não dedicam um

$3{ }^{5}$ Ao se pesquisar, como termo exato, "direito e economia" nos campos nome, linha de pesquisa ou palavra-chave dos grupos certificados e atualizados no Diretórios de Grupos de Pesquisa no Brasil do CNPQ, localizaram-se dezesseis grupos, com distintos escopos e origens: Análise Econômica do Direito (PUC/PR); Centro de Estudos Jurídico-Econômicos e de Gestão do Desenvolvimento (UFSC); Controladoria e Finanças (UNIFAL/MG); Direito Constitucional nas Relações Privadas (UNIFOR); Direito e Desenvolvimento (FEEVALE), Direito e Economia (FGV); Direito e Economia (IDP); Direito e Economia do Petróleo, Gás e outras Fontes de Energias (UCAM); Direito Estado e Sociedade (UFRN); Estado, Sociedade e Relações Jurídicas Contemporâneas (FURB); Estruturas dos Sistemas Tributários e suas Implicações no Desenvolvimento e na Performance do Comércio Exterior dos Países do BRIC: Lições e Soluções (UCB/DF); História e direito: da civilização ao desenvolvimento no Brasil 1750-1930 (USP); Núcleo de Direito, Economia e Governança (FGV); Núcleo de Estudos em Direito Economia, NEDE-DF (UniCEUB); O Papel das Agências Reguladoras no Desenvolvimento da Infraestrutura (UCAM); Propriedade Intelectual, Inovação e Desenvolvimento (UCAM). Dados disponíveis em: < http://lattes.cnpq.br/web/dgp>. Acesso em: 26 out. 2015. Apenas pelos nomes não é possível a identificação de qualquer um dos grupos com dedicação à AED do DIP.

$4{ }^{6}$ Reconhece-se o quão indeterminado possa vir a ser o termo "academia brasileira". Acadêmicos brasileiros no Brasil? Acadêmicos, nacionais ou estrangeiros, que lecionam no Brasil? Adotou-se como critério artigos de acadêmicos, independentemente de sua nacionalidade, com algum tipo de vinculação a uma IES no Brasil. Vejam-se: BELONIEL, Daniel; SALAMA, Bruno. Towards an intellectual property bargaining theory: the post-wto era. University of Pennsylvania Journal or International Law, v. 32, n. 1, p. 265-368, 2010; SANTOS, Alexandre Leite. O direito internacional público como jogo institucional. Economic Analysis of Law Review, v. 1, n. 2, p. 179-195, July/Dez. 2010; RIBEIRO, Gustavo Ferreira. The legality of trade sanctions based on human rights violations: an analysis through law and economics. Economic Analysis of Law Review, v. 3, n. 2, p. 260-281, Dez. 2012; CAIADO, José Guilherme Moreno. From coordination to collaboration: explaining international disputes over tariff classification. Economic Analysis of Law Review, v. 3, n. 1, p. 95-108, Jun. 2012; ELTZ, Magnum Koury de Figueiredo. Uma abordagem da análise econômica do direito para os danos ambientais transfronteiriços. Economic Analysis of Law Review, v. 3, n. 1, p. 40-56, Jun. 2012.

5 Em ordem cronológica: TIMM, Luciano (Org.). Direito e economia. Porto Alegre: Livraria do Advogado, 2008 (contendo um capítulo específico de direito internacional privado, sob a autoria do professor Paulo Caliendo); SALAMA, Bruno Meyerhof (Org.). Direito e economia: textos escolhidos. São Paulo: Saraiva, 2010. (Direito em Debate); COOTER, Robert; ULEN, Thomas. Direito e economia. 5. ed. Porto Alegre: Bookman, 2010. RIBEIRO, Gustavo Ferreira; GICO JR, Ivo T. (Org.). O jurista que calculava. Curitiba: CRV, 2013; TIMM, Luciano (Org.). Direito e economia no Brasil. 2. ed. São Paulo: Atlas, 2014. (contendo um capítulo específico de direito internacional privado, sob a autoria da professora Nádia de Araújo). 
único capítulo sobre o tema.

Decerto, ao menos três motivos contribuem para explicar o cenário mencionado. Em primeiro lugar, esse é um campo novo de pesquisa, exigindo algum tempo para que os grupos especializados em AED e/ou DIP, respondam com publicações e trabalhos na área. Em segundo lugar, o método utiliza, ao se interpolar com a ciência econômica, premissas como racionalidade, escassez, bem-estar, eficiência, teoria dos jogos e ferramentas matemáticas pouco conhecidas na tradição do ensino do DIP, e por que não, do direito, no Brasil. Como resultado, há uma carência de docentes e publicações com viés interdisciplinar que poderiam impulsionar seu uso. ${ }^{6}$ Por fim, mesmo se apropriando desses conhecimentos, existem desentendimentos acerca das possibilidades e limites do método, o que pode dificultar seu uso e aceitação por parte da academia.

As escolas norte-americanas possuem maior familiaridade com a $\mathrm{AEDIP}^{7}$, uma vez que é precursora da AED de forma geral ${ }^{8}$. Já a tradição europeia, assim como a brasileira, é menos aberta ao método, embora o quadro venha se alterando. Aaken, quanto ao cenário europeu, reconhece a sua "quase totalmente negligenciada" utilização. A autora credita essa ausência à tensão da visão kantiana do direito internacional com o pensamento consequencialista e a percepção de que a principal função do jurista é o trabalho dogmático-doutrinário. ${ }^{?}$

6 Aliás, parece ser um problema de "mão dupla", podendo-se dizer que aos economistas também lhes falta maior compreensão da argumentação jurídica e das categorias axiológicas do direito.

7 Sem se pretender qualquer tipo de exaustão, citam-se como seminais: SYKES, Alan O. Protectionism as a "safeguard": a positive analysis of the gatt "escape clause" with normative speculations. University of Chicago Law Review, v. 58, n. 1, p. 255-306. winter 1991; DUNOFF, Joel L.; TRACHTMAN, Jeffrey P. Economic analysis of international law. Yale Journal of International Law, v. 24, n. 1, p. 1-59, winter 1999; BHANDARI, Jagdeep S.; SYKES, Alan O. (Org.). Economic dimensions in international law comparative and empirical perspectives. Cambridge: CUP, 1998. Mais recentemente, GOLDSMITH, Jack L.; POSNER, Eric A. The limits of international law. Oxford: OUP, 2005; TRACHTMAN, Joel P. The economic structure of international law. Cambridge: HUP, 2008; GUZMAN, Andrew T. How international law works. Oxford: OUP, 2008; TRACHTMAN, Joel P. The future of international law: global government. Cambridge: CUP, 2013. POSNER, E. A.; SYKES, A. O.; POSNER, Eric A; SYKES, Alan O. Economic foundations of international law. Cambridge: HUP, 2013.

$8{ }^{10} \mathrm{Não}$ é objetivo deste artigo citar a numerosa literatura de AED nos Estados Unidos, mas deve-se apenas se lembrar as contribuições de Coase, Becker e Williamson, para a formação da área.

$9{ }^{11}$ VAN AAKEN, Anne. Opportunities for and limits to an economic analysis of international economic law. Law and Economics Re-
O artigo se desenvolve, inicialmente, por localizar a AEDIP como um método e expondo dois de seus pressupostos chave: escassez e racionalidade. $\mathrm{Na}$ sequência, investe-se na aplicação da AEDIP em problemas relativos às fontes do direito internacional (tratados e costumes) e a dois de seus campos específicos (investimentos e direitos humanos). Conclui-se por reconhecer os benefícios e desafios do método, conquanto superáveis, que resultariam em uma aproximação salutar da academia brasileira com o vanguardismo no estudo do direito internacional.

\section{A AED COMO UM METOdOLOGIA E SUAS PAR- TICULARIDADES}

\subsection{A análise econômica do direito como um mé- todo aplicável ao direito internacional público}

Os métodos na ciência jurídica são objeto de intenso debate e divergência. Em simpósio realizado em 1999, no contexto da academia norte-americana, Ratner e Slaughter retomaram esse debate secular indicando a AED como um dos sete métodos aplicados a problemas de direito internacional. ${ }^{10}$

A enumeração ${ }^{11}$ parece agrupar, sem maior rigor, escolas, métodos e movimentos ao colocá-los conjuntamente. Reflete uma opção pragmática dos organizadores que chegam mesmo a se questionar se o DIP possui um único ou múltiplos métodos. ${ }^{12}$ Para eles, a preocupação do simpósio sobre o que era um método era menos o de associá-lo a uma teoria geral de direito internacional que pudesse explicar a natureza do DIP, mas o de buscar, na prática, como cada método responderia a problemas específicos. Nessa sistemática,

search Paper Series, v. 9, n. 31, 2010. p. 2.

10 12RATNER, Steven R.; SLAUGHTER, Anne Marie. Appraising the methods of international law: a prospectus for readers. American Journal of International Law, v. 93, n. 2, p. 291-302, April 1999. p. 300.

11 Além da AED (ou law and economics), enumeraram-se: o positivismo; o da escola de New Haven; o processo legal internacional (international legal process); os estudos jurídicos críticos (Critical Legal Studies - CLS); o método que combina o direito internacional e as relações internacionais.

$12{ }^{14}$ RATNER, Steven R.; SLAUGHTER, Anne Marie. Appraising the methods of international law: a prospectus for readers. American Journal of International Law, v. 93, n. 2, p. 291-302, April 1999. p. 299. 
ofereceu-se um mesmo problema para os representantes de cada "método" para que eles determinassem, entre outras coisas, "porquê o direito é daquela maneira", "qual deveria ser o direito" e "qual é o direito" aplicável ao caso. ${ }^{13}$ Como se sugerirá neste artigo, as perguntas refletem as perspectivas positiva, normativa e hermenêtica, com distintas visões sobre os limites e possibilidades de contribuição da AEDIP.

A AED, em si, é descrita como um método que, na sua vertente aplicada ao direito interno, provou-se altamente relevante e duradoura, sob duas formas. A positival descritiva, que serve para explicar as normas como reflexo de resultados economicamente mais eficientes. A normativa, que possibilita avaliar propostas de mudanças nas normas, instando a adoção daquelas que maximizam a riqueza. O método seria frequentemente entendido por abarcar a teoria dos jogos e a escolha pública e, na área internacional, teria estreado com estudos de questões internacionais de comércio e meio-ambiente. A AED possuiria, ademais, relação próxima ao método que conjuga direito internacional e relações internacionais ao dar prioridade ao comportamento racional dos atores. $^{14}$

A categorização entre AED com perspectiva positival descritiva e normativa remonta períodos mais longínquos, própria da epistemologia das ciências sociais, com transposição específica ao direito e ao DIP. Em conferência realizada uma década após a norte-americana, sob os auspícios da Sociedade de Direito Internacional Econômico (SIEL), Aaken relembra que, tradicionalmente, existem três perspectivas de estudar o direito com reflexo direto na abordagem dos juristas. Com alusão ao pioneirismo classificatório de Kantorowicz, cita a autora a perspectiva sociológica (ciência positiva, descritiva), a normativa (ciência normativa) e a doutrinária. Para a autora, partindo do ponto de vista do observador, as perspectivas sociológica e normativa da AEDIP funcionam como uma visão externa, mais característica das ciências sociais. Já à visão interna corresponderia a perspectiva doutrinária, comumente aplicada por juristas para a inter-

13 15RATNER, Steven R.; SLAUGHTER, Anne Marie. Appraising the methods of international law: a prospectus for readers. American Journal of International Law, v. 93, n. 2, p. 291-302, April 1999. p. 292.

$14{ }^{16}$ RATNER, Steven R.; SLAUGHTER, Anne Marie. Appraising the methods of international law: a prospectus for readers. American Journal of International Law, v. 93, n. 2, p. 291-302, April 1999. p. 294, 300. pretação das normas. ${ }^{15}$

A autora reforça o caráter da perspectiva sociológical positiva como descritiva, explanatória e preditiva. De forma geral, nela se desenvolve uma hipótese que deve ser empiricamente testada. Já a abordagem normativa inclui, no caso do DIP, a questão de como ele deve ser (lege ferenda). Em um nível mais geral, aproxima-se da filosofia ao se questionar quais objetivos deve o DIP buscar (eficiência, paz, justiça, sustentabilidade). Em seu nível mais específico, pode ser usado para se pensar como conceber instituições internacionais (em sentido amplo: organizações, tratados, softlaw) tendo em vista certos objetivos, inclusive a efetividade da norma internacional. Finalmente, a abordagem doutrinária teria relação com a aplicação do direito (bermenêutica) e, no caso singular do DIP, com os artigos 31 e 32 da Convenção de Viena dos Direitos dos Tratados (CVDT). ${ }^{16}$

Ao fazer a categorização em três perspectivas, não teve a autora intenção de considerá-las estanques. Pelo contrário. Sugere que as perspectivas são intimamente interconectadas. A abordagem positiva pode resultar em uma crítica normativa. Ou seja, ao se descrever algo (pela ciência positiva) afloram seus benefícios e problemas, podendo se sugerir aproveitamentos e mudanças; o esforço normativo (p.e. na concepção de políticas públicas e instituições internacionais), por sua vez, necessita da descrição sociológica (ciência positiva) se se quer levar em conta os efeitos de normas no mundo real.

Até esse ponto, parece que Aaken entende não haver maiores dificuldades no papel das ciências sociais (incluindo a economia) a contribuir pelas interconexões das perspectivas. Porém, sobre a terceira abordagem (hermenêutica), revela a autora maior divergência entre a tradição europeia (refratária ao uso de outras disciplinas que não o direito) a e norte-americana (familiar ao uso das ciências sociais no direito) com reflexos no DIP. Ao mesmo tempo, admite Aaken certo contrassenso na tradição continental. Afinal, certos métodos interpretativos (como o teleológico, prescrito no artigo 31(1), in fine da CVDT, "[...] à luz de seu objetivo e finalidade") não apenas deixa aberto uma janela para conhecimentos das ciências sociais (positivos ou normativos) mas mesmo de-

$15{ }^{17}$ VAN AAKEN, Anne. Opportunities for and limits to an economic analysis of international economic law. Law and Economics Research Paper Series, v. 9, n. 31, 2010. p. 4.

$16{ }^{18}$ VAN AAKEN, Anne. Opportunities for and limits to an economic analysis of international economic law. Law and Economics Research Paper Series, v. 9, n. 31, 2010. p. 6. 
manda-o. $\mathrm{O}$ mesmo ocorreria com relação à argumentação de natureza consequencialista e certos princípios como o da proporcionalidade e da necessidade, encontrados no General Agreement on Trade and Tariffs (GAT'T) e na Convenção Europeia de Direitos Humanos. Esses métodos e princípios funcionariam como "canais" ou "janelas" para se acomodar os cânones da "escolha racional" e os paradigmas das ciências sociais, como a economia. $^{17}$

Em sessão própria, este artigo retomará as classificações e suas aplicações na AEDIP. Porém, duas ressalvas são esclarecedoras ao se tomar a AEDIP como um método, distinguindo-o de outras abordagens envolvendo a economia e o direito internacional.

A primeira é que o uso da economia pode ser meramente acessório à aplicação da regra jurídica. Pense-se, por exemplo, no caso envolvendo o Brasil e os Estados Unidos, na Organização Mundial do Comércio (OMC), sobre a concessão de subsídios pelo governo norte-americano aos seus agricultores. Uma vez considerado proibido, o cálculo do dano que o programa de subsídios norte-americanos ao algodão causou à indústria nacional de diversos países faz apenas uso instrumental da economia. Da mesma forma, quando se autorizou, no mesmo contencioso, que o Brasil retaliasse produtos norte-americanos até um determinado valor (gatilho), a potencial lista de produtos oferecidas pelo Brasil se fundava em um cálculo econômico (elasticidade-renda) de cada um dos produtos da lista.

A segunda observação se direciona à classificação do direito em disciplinas e a associação da AED àquelas vistas como pertencentes exclusivamente ao campo do direito internacional econômico (DIE), i.e., comércio, investimentos e finanças internacionais. ${ }^{18}$ Ainda que o DIE seja um campo fértil para a AED (seja nas perspectivas positiva, normativa e/ou doutrinária), outras áreas

$17{ }^{19}$ VAN AAKEN, Anne. Opportunities for and limits to an economic analysis of international economic law. Law and Economics Research Paper Series, v. 9, n. 31, 2010. p. 7-8.

$18{ }^{20}$ Embora seja igualmente complexo definir qual é o campo do direito internacional econômico. Da academia norte-americana e europeia vejam-se, respectivamente: CHARNOVITZ, Steve. What is international economic law? Journal of International Economic Law, v. 14, n. 1, p. 3-22, 2014. CARREAU, Dominique; FLORY, Thiébault; JULLIARD, Patrick. Droit internacional èconomique. Paris: Persée, 1990. No caso do Brasil, encontra-se, no prelo, abrangente pesquisa empírica dos professores Fabio Costa Morosini (UFRGS) e Michelle Ratton Sanchez Badin (FGV), sobre o escopo de campo do DIE, com base nos currículos lattes dos professores que se auto intitulam como pertencentes à disciplina. não percebidas como diretamente econômicas também podem ser. Ratner e Slaughter mencionam que a Corte de Justiça Internacional (CIJ) vem há muito tempo considerando a eficiência econômica como um conceito chave em seus julgamentos, citando especificamente, em sua ilustração, o caso da delimitação das plataformas continentais trazidos àquela Corte. ${ }^{19}$

Exposta a AEDIP como um método e suas perspectivas, as próximas seções avançam na elaboração de dois de seus pressupostos chave (escassez e racionalidade).

\subsection{Pressuposto chave: escassez}

A economia é tida como a ciência que trata da alocação de recursos escassos. Qualquer manual ou livro consistente de introdução à economia enfatizará, de uma outra maneira, a escassez como um fato.

Assim, Cooter e Ulen relembram a consagrada definição de ciência econômica em Robbins: trata-se do estudo do "comportamento humano como uma relação entre fins e meios escassos que poderiam ser usados de modo alternativo". ${ }^{20}$ Pindick e Rubinfeld dão sonoridade (e simplicidade) à definição, aludindo à canção dos Rolling Stones de que "não se pode conseguir sempre [tudo] aquilo que se deseja". ${ }^{21}$ No campo do direito, Holmes e Sustein já salientaram a dupla relação entre escassez e direitos: (i) direitos dependem da existência de recursos; e (ii) governos e juízes escolhem rotineiramente como alocá-los, sendo que a escolha de se proteger alguns resulta no abandono de outros. ${ }^{22}$ São centenas de variações na literatura para se descrever uma realidade: os recursos na sociedade, doméstica ou internacional, são escassos e há escolhas a serem feitas.

As inferências são imediatas para o plano internacional. Não há recursos suficientes no mundo para, ao mesmo tempo, saciar a fome mundial, eliminar a poluição do mar, conservar as florestas, eliminar o desemprego, acolher refugiados, eliminar o tráfico internacional

$19{ }^{21}$ RATNER, Steven R.; SLAUGHTER, Anne Marie. Appraising the methods of international law: a prospectus for readers. American Journal of International Law, v. 93, n. 2, p. 291-302, April 1999. p. 300.

$20{ }^{22}$ COOTER, Robert; ULEN, Thomas. Direito e economia. 5. ed. Porto Alegre: Bookman, 2010. p. 35.

$21{ }^{23}$ PINDYCK, Robert S.; RUBINFELD, Daniel L. Microeconomia. 7. ed. São Paulo: Pearson, 2010. p. 4.

$22{ }^{24}$ HOLMES, Stephen; SUNSTEIN, Cass R. The cost of rights: why liberty depends on taxes. New York: WW Norton, 1999. capítulo 5 . 
de crianças, garantir a paz, entre outros. Escolhas serão feitas e as discussões passam pela legitimidade dessas escolhas e de como os atores, se se deseja atingir o objetivo com o menor desperdício possível de recursos, podem maximizar os resultados pretendidos.

Outra questão nessa transposição é a da identidade dos atores que, assumidamente e racionalmente, realizam essas escolhas em um mundo escasso. O DIP concede intensa primazia ao papel do Estado, uma coletividade, em sua análise. O que significaria racionalidade e como pensá-la nesse contexto?

\subsection{Pressuposto chave: racionalidade}

O método econômico faz uso do conceito de racionalidade e, por consequência, da escolha racional (rational choice), comumente empregado nas ciências sociais. Os atores são racionais e suas ações são pautadas por cálculos de custos e benefícios de acordo com seus interesses ou preferências. Diz-se que os atores (os mais variados possíveis) buscam maximizar o resultado final do cálculo (benefício líquido), de acordo com essas preferências.

Não se tratam de cálculos puramente monetários e passa despercebido pelos juristas a idiossincrasia de que a própria ordem jurídica se funda na ideia de gerar custos e benefícios que influenciam o balanceamento dos cálculos pelos atores. A sanção (administrativa, civil ou penal) pode ser pensada como uma forma de se criar custos, ao desincentivar condutas dos agentes. Normas premiais induzem o inverso. Da mesma forma, decisões judiciais geram uma espécie de segunda ordem de efeitos na sociedade sinalizando o que é ou não aceitável, sendo a de primeira ordem aquela específica ao caso concreto, entre as partes. Não há aqui, reforce-se, o intento de se desenvolver os meandros desses pressupostos, mas simplesmente de sugerir transposições para a AEDIP.

Decerto, a racionalidade permite que o pesquisador entenda o comportamento de diversos atores como racionais, ainda que esses não sejam formalmente reconhecidos como sujeitos de direito internacional. Assim, mesmo que grande parte da literatura da AEDIP tenha por objeto de pesquisa o comportamento estatal, seja como formulador ou objeto da norma jurídica, também é possível analisar o comportamento, bem como o impacto de uma determinada norma sobre o comportamento de várias outras coletividades: organizações internacionais, grupos governamentais informais, organizações-não-governamentais, tribunais internacionais e domésticos e empresas multinacionais.

Ao fazer simplificações, como em qualquer método, e considerar o Estado como a unidade de análise racionalizadora, sem desagregá-la, a AEDIP nada mais faz do que uma redução metodológica. O mesmo ocorre em outras abordagens. Nas relações internacionais, similarmente, a unidade de análise "Estado" é tida como dada (taken as given). Na escola realista, o foco é no Estado que busca maximizar seu poder no plano internacional, ${ }^{23}$ colocando-se de lado o papel dos grupos domésticos internos na formação dos interesses. De forma análoga, mas com foco em elementos outros que o poder, os institucionalistas também veem o estado como uma "caixa preta", conferindo pouca ênfase à influência de grupos políticos domésticos.

O questionamento de como as preferências e/ou interesses dos Estados são forjados conduzem a inúmeras discussões que podem ser introduzidas em modelos mais sofisticados. Se se prefere uma abordagem político-econômica, pode-se entender a racionalidade da ação estatal com base em um conjunto de forças domésticas, o que é estudo do campo denominado Escolha Pública (Public Choice) ou de outras escolas das relações internacionais (Liberal Theory).

Mas ao se considerar o Estado (unidade de análise) como um ente racional, paralelos serão possíveis para se entender o significado do agir racional. Por exemplo, se se pensa nas razões às quais Estados celebram tratados, como sugere Guzman, Estados celebram tratados pelo mesmo motivo que indivíduos celebram contratos: obter um excedente cooperativo e garantir o curso de uma conduta presente e futura. ${ }^{24}$ Oportunamente, este artigo retomará esses exemplos.

\subsection{Crítica aos pressuposto racional}

Se da escassez não decorrem críticas plausíveis, a ideia de racionalidade de atores, entretanto, é há muito

$23{ }^{25}$ NOGUEIRA, João Pontes; MESSARI, Nizar. Teoria das relações internacionais. São Paulo: Elsevier, 2005. p. 23-24.

$24{ }^{26}$ GUZMAN, Andrew T. How international law works. Oxford: OUP, 2008. p. 121. São simplificações, reduções, opções metodológicas que funcionam para possibilitar uma análise, mas que não passam despercebidas da crítica da própria AEDIP. GOLDSMITH, Jack L.; POSNER, Eric A. The limits of international law. Oxford: OUP, 2005. p. 4-7. DUNOFF, Joel L.; TRACHTMAN, Jeffrey P. Economic analysis of international law. Yale Journal of International Law, v. 24, n. 1, p. 1-59, winter 1999. p. 16. 
criticada. ${ }^{25}$ Essa tendência, comum em estudos sobre a escolha racional no direito doméstico, na qual se reconhecem lapsos, comportamentos impulsivos e limitações cognitivas dos indivíduos avança, igualmente, sobre a AEDIP.

De acordo com Broude, a abordagem behaviorista diverge da AEDIP "clássica", primeiro por trabalhar com conceitos lastreados em pesquisas empíricas, e também porque os resultados dessas pesquisas demonstram as limitações do conceito de racionalidade, tão caro aos estudiosos da análise econômica. Segundo os argumentos de Broude, a ideia de racionalidade da análise econômica estaria tão desgastada, que a análise behaviorista deveria se aproximar mais da sociologia que da análise econômica racional. Esse behaviorismo sociológico, na opinião de Broude, poderia abrir novas frentes de pesquisa no estudo do DIP, podendo ser aplicado para compreender o comportamento de três tipos de atores: (i) o estado como ator unitário; (ii) coletividades internacionais de tomada de decisões; e (iii) o indivíduo como tomador de decisões de cunho internacional. ${ }^{26}$ Embora pertinente o argumento, entende-se que não há na AEDIP uma exclusão a priori dessas dimensões. Como já se mencionou, trata-se muito mais

$25{ }^{27} \mathrm{Um}$ bom resumo é a discussão de Mark Blaug sobre o postulado da "racionalidade" como sacrossanta, ultra empirista e, como próprio Popper admitiu, falsa. BLAUG, M. The methodology of economics: or how economists explain. 2. ed. Cambridge: CUP, 1992. p. 229-236.

$26{ }^{28}$ BROUDE, Tomer. Behavioral International Law. Hebrew University of Jerusalem International Law Forum Research Paper, n. 12-13, p. 1-85, 2013. doi: 10.2139/ssrn.2320375. De fato, as possibilidades são múltiplas o incremento de experimentos, nos quais se simula, em laboratório ou em campo, o comportamento e a reação de diferentes atores a determinadas situações parece ser uma tendência. Entretanto, ainda que esses métodos possam ser valiosos para se estudar o comportamento de, por exemplo, negociadores internacionais durante as tratativas para assinatura de um acordo, sua aplicação a entes mais complexos, como o Estado e OIs, esbarra na dificuldade de se comparar a ação de tal ente à "falhas" habitualmente observadas no comportamento do indivíduo. Uma das soluções propostas, a de individualizar o comportamento dos estados, pode ser encontrada no trabalho de Hafner-Burton e outros, que analisa uma possível correlação entre a escolha de mecanismos de execução de tratados internacionais e o nível de senioridade dos negociadores americanos. Segundo os autores, quanto mais sênior o negociador, menor a preocupação com tais mecanismos. HAFNER-BURTON, Emilie M.; LEVECK, Brad L.; VICTOR, David G. Strategic enforcement: results from an elite survey experiment on international trade agreements. SSRN Electronic Journal, Aug. 2012. doi: 10.2139/ ssrn.2132948. Available at: <https://www.researchgate.net/publication/256031577_Strategic_Enforcement_Results_from_an_ Elite_Survey_Experiment_on_International_Trade_Agreements $>$. Access: Feb. 09, 2016. de uma questão de enfoque, de modelagem e do tipo de problema que se quer analisar.

Não é por menos, que, atenuando a crítica acerca do papel da teoria racional para a compreensão do direito internacional, Aaken sugere que a abordagem behaviorista pode oferecer argumentos e conclusões complementares aos resultados da análise econômica. Por exemplo, trazendo insights acerca da pretensão de Estados, representados na figura de seus negociadores, de assinarem tratados internacionais. Segundo a autora, a teoria behaviorista sugere que a vinculação de negociações de diferentes tratados (bens manufaturados, produtos agrícolas, serviços, meio-ambiente), como no caso da OMC, pode ser um empecilho à conclusão das tratativas, porque indivíduos tendem a supervalorar suas concessões, e subestimar aquelas feitas pela outra parte. Se essa supervaloração já tem implicações em um contrato simples entre duas partes, ela se potencializa em contratos múltiplos que precisam ser negociados simultaneamente entre partes diversas. Outro problema, baseado na teoria contratual, diz respeito aos benefícios de flexibilidade nos contratos, que é comumente defendida pela teoria racional. De acordo com Aaken, há uma tendência de que as partes interpretem a seu favor cláusulas demasiadamente abertas, o que pode levar a comportamentos contra produtivos do ponto de vista da criação esperada de valor pelo contrato. Assim, as recomendações da teoria behaviorista acerca da rigidez contratual podem diferir daquelas da teoria racional pu$\mathrm{ra.}^{27}$

$\mathrm{Na}$ seção subsequente, apresentado o método da AEDIP e os pressupostos da escassez e racionalidade, sugerem-se contribuições do método a problemas específicos.

\section{Potencials contribuições da AEDIP}

A presente seção expõe, principalmente, quatro aplicações da AEDIP. Nas duas primeiras, ilustra-se a teoria das fontes do direito internacional público vista sob o olhar da teoria racional: por que certas formas jurídicas surgem e quando estas serão preferidas sobre outras (tratados e costumes, nos exemplos dados). Nas

$27{ }^{29}$ VAN AAKEN, Anne. Behavioural international law and economics. Harvard International Law Journal, n. 55, p. 421-481, summer 2014. 
duas seguintes a AEDIP é aplicada à determinadas áreas do DIP: direito internacional dos investimentos e direitos humanos. Em cada um dos exemplos, apontam-se a qualidade da abordagem em positiva, normativa ou hermenêutica, retomando-se as distinções anteriores. Como fechamento do bloco, enumeram-se outras possíveis aplicações.

\subsection{Tratados: por que se formam? Por que se descumprem?}

Fonte formal do DIP, os tratados são definidos como um acordo internacional concluído por escrito entre Estados e regido pelo Direito Internacional, podendo se consubstanciar em um único ou múltiplos instrumentos. As variações terminológicas (como convenções) são irrelevantes, sendo esse o conceito encontrado na Convenção de Viena dos Direitos dos Tratados. Do texto convencional se desenvolve boa parte do dogmatismo jurídico acerca dessa fonte; por assim dizer, as regras sobre a conclusão e a entrada em vigor, a possibilidade de reservas, a observância, a aplicação e a interpretação dos tratados.

Em uma de suas aplicações, a AEDIP pode ser utilizada para se desvendar a origem dos tratados. Por que Estados se engajam na celebração de tratados? Ou qual a origem material dos tratados? ${ }^{28}$

Trata-se da perspectiva positiva da AEDIP que nos ajuda a compreender essas indagações, amparando-se na dinâmica racional Estatal. Alguns autores utilizam a teoria dos contratos, que já recebeu bastante atenção por parte da literatura doméstica de análise econômica, nesse esforço. Como sugere Trachtman, tratados devem ser vistos como análogos aos contratos domésticos porque são, também, acordos entre partes com a intenção de criar-se um documento juridicamente vinculante com direitos e obrigações que modelem o comportamento futuro das partes. ${ }^{29}$

\footnotetext{
$28{ }^{30}$ A distinção entre fonte formal e material dos tratados é didaticamente feita pelo professor Guido Soares com a analogia de uma pessoa que busca água para matar sua sede: "vai à fonte (fonte formal), sem ter de preocupar-se com a indagação de sua origem mais profunda (fonte material), ou seja, se a mesma vem de lençóis freáticos, [...] do ciclo de água da terra, [...] a partir do big-bang que formou o universo [...]"SOARES, Guido Fernando Silva. Curso de direito internacional público. 2. ed. São Paulo: Atlas, 2004. v. 1. p. 54.

$29{ }^{31}$ DUNOFF, Joel L.; TRACHTMAN, Jeffrey P. Economic analysis of international law. Yale Journal of International Law, v. 24, n. 1, p. 1-59, winter 1999. p. 23.
}

Ainda sob o pensar positivo, a AEDIP oferece ferramentas sobre as razões pelas quais os tratados são descumpridos e como a racionalidade da inobservância se afeiçoa. Ao se abordar contratos a partir da teoria dos preços, argumenta-se que o preço (custo) de violação é o elemento principal da observância. Esse preço seria composto por dois elementos. Em primeiro lugar, a quantidade ou valor dos danos que um determinado Estado teria de arcar em caso de inobservância. Em segundo lugar, a probabilidade de condenação. Essa, por sua vez, seria afetada pela capacidade de se (i) identificar um comportamento ilícito, e de se (ii) provar sua existência perante o tribunal competente. Se a resultante da composição (multiplicação) das variáveis valor e probabilidade for demasiadamente baixa, podem se esperar incentivos baixos para o cumprimento das obrigações firmadas.

Porém, em uma sociedade global anárquica, horizontal - sem autoridade central - pode-se mesmo especular se o tratado teria o condão de induzir observância (cumprimento) das obrigações internacionais com base apenas na composição das variáveis acima. Transposto para a linguagem jurídica, vem à tona o tradicional problema da "ausência" de sanção e enforcement do DIP.

Não é por menos que Guzman teoriza sobre a existência de três " $R$ " (reputação, reciprocidade e retaliação) como componentes necessários à análise sobre a observância das obrigações internacionais. A reputação é definida como a avaliação sobre o comportamento passado de um determinado ator para se prever seu futuro comportamento. Assim, uma "sanção" reputacional se refere ao custo imposto ao Estado quando sua reputação é atingida negativamente. Não se tratam de punições no sentido estrito, mas a ideia da perda de credibilidade do Estado frente a seus pares. Quando um Estado observa (cumpre) um tratado transmite uma mensagem de que tem boa vontade em honrar suas obrigações. Essa boa reputação teria valor ao tornar mais críveis e menos custosos novos compromissos com esse Estado. ${ }^{30}$ Colocado simplificadamente, acredita-se em quem goza de boa reputação, sendo o inverso também verdadeiro. A reciprocidade, similarmente, não representa uma "sanção" direta ao violador, mas uma resposta ao descumprimento do violador original: um Estado cessa o cumprimento de suas obrigações (descontinua a reciprocidade) quando a violação original não mais atende

$30{ }^{32}$ GUZMAN, Andrew T. How international law works. Oxford: OUP, 2008. p. 33. 
a seus interesses. Finalmente, a retaliação possuiria o intento direto de punir o violador, perpassando pelas formas de sanções econômicas, diplomáticas ou mesmo militares. $^{31}$

Também dessa visão descritiva, são trazidos conceitos de incompletude dos contratos causada por conhecimento insuficiente das partes ou por cálculo estratégico no momento das negociações. ${ }^{32}$ Nesse ponto, extrapola-se a mera narrativa do tratado como fonte material do DIP e se investiga a questão das variações obrigacionais dos tratados (precisas, imprecisas, de melhores esforços etc.).

Pode se chegar a uma situação, assim segue o argumento, em que os custos de transação na negociação contratual sejam muito elevados e as partes decidam empregar termos vagos que carecem de interpretação, ou simplesmente ignorem certos possíveis comportamentos ou situações futuras que demonstrem necessidade de regulação. Os juristas rotulam o resultado dessa dinâmica como cláusulas abertas, conceitos indeterminados ou a ideia de ambiguidade construtiva dos tratados (constructive ambiguity). Haveria, portanto, na esfera bermenêutica e como prescrição normativa a possibilidade de que os tribunais empreguem uma regra que, alegadamente, as partes teriam alcançado nas negociações. Alternativamente, que se determinem sanções que poderiam levar a um comportamento similar ao que teria sido estabelecido pelas partes, colocando-as na mesma posição caso as obrigações tivessem sido cumpridas. ${ }^{33}$

Paradoxalmente, em uma perspectiva normativa, alguns estudiosos afirmam que, em certas circunstâncias, a inobservância de determinada obrigação contratual poderia ser mais eficiente do que o desempenho da obrigação pactuada no tratado. ${ }^{34}$ Os economistas se utilizam de certos conceitos de eficiência (Pareto e Kaldor-

$31{ }^{33}$ GUZMAN, Andrew T. How international law works. Oxford: OUP, 2008. p. 33-34.

$32{ }^{34}$ SANTOS, A. L. O direito internacional público como jogo institucional. Economic Analysis of Law Review, v. 1, n. 2, Dez. 2010, p. 186, 193.

33 35 Para uma análise mais detalhada acerca da aplicação dessa teoria ao direito internacional. PAUWELYN, Joost. Optimal protection of international law: navigating between European absolutism and American voluntarism. Cambridge: CUP, 2008.

$34{ }^{36}$ SYKES, Alan O. Protectionism as a "safeguard": a positive analysis of the gatt "escape clause" with normative speculations. University of Chicago Law Review, v. 58, n. 1, p. 255-306. winter 1991. Para uma análise mais recente, ver SCHROPP, Simon. A. B. Trade policy flexibility and enforcement in WTO: a law and economics analysis. Cambridge: CUP, 2009.
-Hicks) $)^{35}$ para estabelecer o porquê de ser a quebra um resultado eficiente (efficient breach), atendidas certas condições. $^{36}$

Ao mesmo tempo, exerce-se uma crítica normativa por meio da descrição positiva, no sentido de que a quebra eficiente pode afetar o núcleo duro da teoria dos tratados, ou seja, a noção de que os tratados têm de ser obedecidos. ${ }^{37}$ Dessa leitura, afirmariam os juristas: "pacta sunta servanda".

\subsection{O direito consuetudinário}

$\mathrm{Na}$ dogmática internacionalista, o direito consuetudinário é definido como uma de suas fontes formais. Da leitura do artigo 38 do Estatuto da Corte Internacional de Justiça, advém o conceito tradicional do costume como prova de uma prática geral aceita como sendo o direito. A doutrina, com variantes, distingue dois elementos dessa definição: (i) a prática consistente entre os Estados; e (ii) a opinio iuris, elemento subjetivo associado à consciência ou aceitação do costume como sendo o direito.

Encontram-se bem documentados os enigmas acerca da definição e prova do costume (duração, abrangência da prática, significado da opinio iuris). A abordagem dogmática, entretanto, empenha poucos esforços em explanar a razão do surgimento dos costumes internacionais, podendo-se questionar até mesmo se teria essa função, ao tomar o costume como fonte formal e não material. $^{38}$

A AEDIP positiva, por outro lado, retoma a proble-

35 A lição de SEN é um bom ponto de partida sobre os diversos conceitos de eficiência. Veja-se: SEN, Amartya. On ethics and econom ics. Malden: Blackwell, 1987. p. 31-40, sem se olvidar da leitura de suas diversas notas de rodapé.

36 Trazido para a linguagem jurídica, o debate é feito à luz da colisão de princípios (por exemplo, o pacta sunt servanda e o rebus sic stantibus). Como consequência, poder-se-ia argumentar que o direito internacional deveria permitir a violação da obrigação em tais casos. $37{ }^{39}$ Entretanto, os autores argumentam que, no direito interno esse também é um problema e que a doutrina concluiu que ao permitir quebra eficientes pode-se estimular as partes a celebrar contratos que não existiriam em sua ausência. DUNOFF, Joel L.; TRACHTMAN, Jeffrey P. Economic analysis of international law. Yale Journal of International Law, v. 24, n. 1, p. 1-59, winter 1999. p. 24-26. $38{ }^{40}$ Estar-se-á aqui incorrendo nos riscos das generalizações. Relevante estudo sobre métodos no direito internacional e a conjugação de explicações dogmáticas e realistas sobre o costume internacional é encontrada em LUPI, André Lipp Pinto Basto. Os métodos no direito internacional. São Paulo: Lex, 2007. p. 173-201. 
mática de se explicar o costume como fonte material do DIP. Em uma das pioneiras abordagens, Goldsmith e Posner rejeitam argumentos de jusnaturalismo e de moralidade para justificar a origem do costume. Adentram o comportamento dos Estados, por meio da teoria dos jogos, para elucidar quatro lógicas possíveis e subjacentes ao surgimento do costume. A primeira, coincidência de interesses, sugere que as regularidades de comportamento associadas ao costume são meros resultados de condutas individuais auto interessadas dos Estados, sem qualquer relevância quanto à ação tomada por outros. A segunda, coerção, tem a ver com o poderio de um Estado (ou coalizão) em forçar ou ameaçar outros pares em se engajar em atos que não fariam, absente a coerção. A terceira (cooperação verdadeira) e a quarta (coordenação) lógicas envolveriam algum grau de incremento de ganhos para os Estados em ações concertadas mas teriam pouco poder explicativo para justificar o costume como uma prática persistente da comunidade internacional, senão em situações particulares com poucos Estados. ${ }^{39}$ Em outras palavras, não haveria costume na esfera internacional fora das hipóteses em que todos fazem parte daquela prática. No extremo do argumento, descartar-se-ia mesmo a noção de jus cogens e a possibilidade de se referir a violação de costumes a Estados que não tenham inequivocamente se comportado como entendendo ser aquele costume o próprio direito.

Guzman, por outro lado, afasta-se da espinhosa questão de buscar a origem do costume. Assume o fato de que tribunais internacionais, como a CIJ, reconhecem um conjunto de costumes na sociedade internacional. Nesse sentido, busca desvendar, também, na perspectiva positiva, em que grau os costumes afetam o comportamento estatal, sugerindo similaridade entre as forças dos "R" presente nos tratados e nos costumes. Tanto as obrigações previstas nos tratados quanto as derivadas do costume gerariam custos aos violadores, seja por perda de reputação, retirada de reciprocidade ou alguma ação retaliatória. Falhas em observar costumes ditos como postos sinalizariam a intenção de um Estado em ignorar obrigações internacionais e faria, em um jogo de continua interação dos Estados ao longo

$39{ }^{41}$ GOLDSMITH, Jack L.; POSNER, Eric A. A theory of customary international law. University of Chicago Law Review, Chicago, v. 66, p. 1133-1177, 1999. p. 1114-1115. Um contra-argumento é apresentado na lição de Schacte de que três ou quatro Estados com frota naval foram responsáveis pela elaboração da maior parte do (costumeiro) Direito do Mar. Veja-se GUZMAN, Andrew T. How international law works. Oxford: OUP, 2008. p. 189. do tempo, que a cooperação futura seja mais custosa (custo reputacional). Já a violação acerca do costume sobre o tratamento de diplomatas estrangeiros ${ }^{40}$ poderia significar a retirada da reciprocidade por outros Estados. Por fim, a inobservância dos costumes acerca de direitos humanos pode, sob a forma de custos de retaliação, desfechar sanções, como comerciais. Além disso, Guzman afirma que os custos de violação dos costumes seriam mais elevados do que os presentes em "meras normas" internacionais que não adquiriram status de costume, embora reconheça a dificuldade em se separar os costumes do que denomina "meras" normas. ${ }^{41}$

Exercitados com a AEDIP, explicações sobre a origem de duas fontes precípuas do DIP, a próxima seção adentra campos específicos de aplicação do método.

\subsection{Direito internacional do investimento}

Sornarajah define o investimento estrangeiro como aquele que "envolve a transferência de ativos tangíveis e intangíveis de um país a outro, com o propósito de utilizá-los neste país gerando riqueza por meio do controle total ou parcial do proprietário dos ativos". ${ }^{42} \mathrm{No}$ jargão jurídico, os direitos envolvendo esse fluxo de capital é estudado sob a disciplina Direito Internacional dos Investimentos.

A literatura é farta. Nela se expõe o potencial conflito entre os interesses dos investidores e as pretensões regulatórias dos países receptores de capital. Ampliada, ostenta esse campo ponderações sobre interesses e ideologias conflitantes entre o Norte e o Sul, países desenvolvidos e em desenvolvimento, embora, recentemente, essa divisão tenha perdido apelo. ${ }^{43}$

Diversas tentativas foram empreendidas em se estabelecer regras sobre investimentos estrangeiros, sendo o gênero Acordos Internacionais de Investimentos (International Investments Agreements - II $A)^{44}$ utilizado para

$40 \quad{ }^{42}$ Acrescentemos: hoje consubstanciado em tratados como a Convenção de Viena das Relações Diplomáticas.

$41{ }^{43}$ GUZMAN, Andrew T. How international law works. Oxford: OUP, 2008. p. 190-193.

$42{ }^{44}$ SORNARAJAH, M. The international law of foreign investment. 3. ed. Cambridge: CUP, 2010. p. 8.

$43{ }^{45}$ A divisão de capital no mundo moderno é muito mais complexa. Basta se pensar o caso do Brasil que, na última década, vêm assumindo uma posição de exportador de capital, buscando o seu próprio modelo de proteção de seus investidores no exterior.

$44{ }^{46}$ Terminologia utilizada pela United Nations Conference on Trade and Development (UNCTAD). 
denominar tanto os acordos bilaterais (BITS), quanto os regionais e multilaterais. Conforme dados da UNCTAD existiram 2.556 desses acordos em vigor (2015), sendo significativa a categoria dos BITS (89\%). ${ }^{45}$

A AEDIP pode ser utilizada em diversas questões sobre o campo do Direito Internacional do Investimento. Como sintetiza SASSE, a estória tradicional dos BITs, quanto a sua origem material, é a de que Estados receptores e investidores estrangeiros buscam gerar algum tipo de excedente (atração de investimento e proteção, respectivamente), por meio desses acordos. Fato, inclusive, que, empiricamente, ainda não se encontra provado. Um número de estudos não conseguiu confirmar os efeitos positivos dos BITS em termos de atração de investimentos. ${ }^{46}$ Há mesmo quem indique, como Montilla, a partir de uma abordagem racionalista (teoria da agência), efeitos negativos, capturados na linguagem econômica como externalidades, que investimentos estrangeiros podem ter em países da África Sub-Sariana. ${ }^{47}$

A abordagem positiva de SASSE, não obstante, indica que os BITs devem trazer, de algum modo, benefícios para as partes e influenciar suas condutas. Do ponto de vista do investidor estrangeiro, o autor localiza os benefícios nos aumentos de custos de violação pelos Estados receptores, em, pelo menos, dois modos. O primeiro se deve à forma particular dos Estados poderem ter seus ativos sequestrados em outros países (em caso de arbitragem); o segundo, pelo custo reputacional, em caso de

$45 \quad{ }^{47}$ Os dados podem ser extraídos do site interativo da UNCTAD: UNITED NATIONS CONFERENCE ON TRADE AND DEVELOPMENT. International Investment Agreements Navigator. Available at: <http://investmentpolicyhub.unctad.org/IIA $>$. Access: Out. $15,2015$.

$46{ }^{48}$ SASSE, Jan Peter. An economic analysis of bilateral investment treaties. Hamburgo: Gabler, 2011. p. 67.

$47{ }^{49}$ No centro da análise desse autor está a ideia de que o direito à propriedade local, com elementos coletivistas, coloca o chefe da tribo em posição possivelmente oportunista em relação aos demais usuários da terra. Estes podem, assim, ter seus interesses mal representados em uma eventual negociação acerca das condicionalidades do investimento. $\mathrm{Na}$ ausência de instrumentos jurídicos locais para fazer valer as pretensões desses usuários, Montilla busca soluções tanto em instrumentos de formulação de tratados de investimento, de interpretação do direito do investimento estrangeiro, bem como na atuação de grupos internacionais sobre o financiamento estatal de tais atividades de aquisição de terra por meio de investimento, como forma de garantir direitos humanos internacionalmente reconhecidos. MONTILLA FERNÁNDEZ, Luis Tomás. Land policies and labour markets in Sub-Saharan Africa: a law and economics analysis. IDS Bulletin, v. 43, n. 6, p. 78-89, 2012. doi: 10.1111/j.17595436.2012.00381.x. violação, frente a outros investidores e Estados-pares. ${ }^{48}$ Como se vê, trata-se de uma aplicação a um campo específico do outrora discutido por Guzman, sobre o funcionamento dos " $\mathrm{R}$ " no direito internacional. ${ }^{49}$

Ainda em uma abordagem descritiva, todavia para explicar a natureza dos BITs como contratos incompletos, Aaken chama a atenção para a incerteza das partes sobre o futuro e os elevados custos na redação do acordo. Destarte, são instrumentos que necessitam de flexibilização. Entretanto, e esse é um ponto de vista mais interessante ao aplicador do direito, a autora classifica a possibilidade da já mencionada quebra eficiente como extralegal. Argumenta que um instrumento de flexibilidade intralegal pode levar a resultados semelhantes, sem a necessidade de modificações no acordo. Os instrumentos intralegais, por sua vez, poderiam ser classificados em explícitos e implícitos. Os explícitos estariam contidos no próprio texto do tratado, tais como regras de exceção contratual. Os implícitos seriam por meio de tribunais e outros mecanismos de interpretação a posteriori que possam vir a, em uma análise de caso concreto, interpretar as regras de maneira a se adequar à nova realidade que possa justificar a violação contratual. Dessa forma, juízes ou outras pessoas designadas pelo tratado poderiam lidar com problemas de incompletude contratual que tenham porventura levado as partes a contratar em termos vagos ou a deixarem lacunas. Uma das soluções, segundo a autora, nesse viés hermenêutico, seria abrir uma porta, com base na interpretação do direito internacional do investimento estrangeiro, para outros campos do direito internacional, como o direito ao meio ambiente ou os direitos humanos. ${ }^{50}$

\subsection{Direitos humanos}

Estudiosos do DIP se deparam com o idealismo não se inferindo necessariamente viés negativo dessa afirmação - e inquirições sobre o campo dos Direitos Humanos na esfera internacional. Sua evolução, força normativa, observância, diferenças entre modelos re-

48 SASSE, Jan Peter. An economic analysis of bilateral investment treaties. Hamburgo: Gabler, 2011. p. 84.

$49{ }^{51}$ Sasse, predominantemente, cita Guzman como parte de seu esforço explanatório. SASSE, Jan Peter. An economic analysis of bilateral investment treaties. Hamburgo: Gabler, 2011.

$50{ }^{52}$ VAN AAKEN, Anne. Smart flexibility clauses in international investment treaties and sustainable development: a functional view. Journal for World Investment and Trade, v. 15, n. 5-6, p. 827-861, 2014. 
gionais e multilaterais, bem como as possíveis implicações para a noção de soberania dos Estados contribuem para que o campo seja polêmico e instigante.

Há quem diga que a AEDIP teria pouco a contribuir, porquanto seus pressupostos (escassez racionalidade e eficiência) colidiriam diretamente com o próprio cerne do campo. Por outro lado, autores relembram a questão dos custos dos direitos ${ }^{51}$ e, no plano internacional, apontam uma verdadeira falta de efetividade dos tratados de direitos humanos. Avançam mesmo, em outro extremo, ao propor a substituição da linguagem de direitos humanos para a de bem-estar humano. ${ }^{52}$

Uma questão inicial seria a de buscar as razões para Estados ratificarem tratados de direitos humanos. Goldsmith e Posner reconhecem-na como um verdadeiro quebra-cabeça. Admitem, desde o início, a diversidade de razões para que Estados se interessem por condições fora de seu território o que pode mesmo estar associado à presença de seus nacionais no exterior, laços religiosos ou étnicos. ${ }^{53}$ Partem, também, do pressuposto que os modernos tratados de direitos humanos (pós Segunda Grande Guerra) não influenciaram significativamente o comportamento dos Estados e se perguntam por que, então, Estados gastam tempo, esforços e recursos para ratificá-los? De um lado, não faria sentido tradicionais democracias liberais ratificá-los. Tampouco, Estados autoritários o fazerem, uma vez que não possuem intenção de cumpri-los. ${ }^{54}$

Os autores não generalizam uma resposta. Ao analisarem especificamente o Pacto Internacional dos Direitos Civis e Políticos, indicam que para democracias liberais haveria um baixo custo associado à sua ratificação, pois já estão em conformidade com o previsto no tratado. Já para os Estados autoritários a falta de mecanismos formais de coação (retaliação) serviria para explicar sua inclinação em ratificá-los. Mesmo ao ponderarem a possibilidade de incorrer em custos reputacionais por

$51{ }^{53}$ HOLMES, Stephen; SUNSTEIN, Cass R. The cost of rights: why liberty depends on taxes. New York: WW Norton, 1999.

$52{ }^{54} \mathrm{O}$ argumento central é que a linguagem de bem-estar (welfare) possuiria maior suporte internacional e filosófico e que a linguagem dos tratados de direitos humanos seria, ao mesmo tempo, rígida e vaga, para guiar as correspondentes políticas públicas. Veja- POSNER, Eric A. Human welfare, not human rights. Columbia Law Review, v. 108, p. 1758-1802, 2008. p. 1758-1763.

$53{ }^{55}$ GOLDSMITH, Jack L.; POSNER, Eric A. The limits of international law. Oxford: OUP, 2005. p. 110-111.

$54{ }^{56}$ GOLDSMITH, Jack L.; POSNER, Eric A. The limits of international law. Oxford: OUP, 2005. p. 127. descumprimento, não haveria maiores diferenças em se ter ou não ratificado o tratado, porquanto ONGs e mídia se encarregariam de estabelecer esse custo reputacional. Os mecanismos do tratado (monitoramento e relatórios) adicionariam apenas custos marginais à violação. Quanto aos benefícios, os autores entendem estar associados ao estabelecimento de um código de conduta ou mesmo um standard civilizatório que poderosas democracias liberais entendem importante propagar. Os benefícios aos Estados cumpridores se associariam ao recebimento de ajudas (acesso a recursos e fóruns do qual não participariam) e a redução de ameaças ou pressões por seguirem este código. ${ }^{55}$

Decerto, as explicações não param por aí. Há, também, a tentativa de atribuir a existência de cooperação relativa a direitos humanos (com ou sem tratados) pelo cálculo sobre os efeitos adversos que uma crise de direitos humanos no exterior pode, eventualmente, ter sobre outros Estados. Uma maneira de se modelar esse problema se dá novamente pela linguagem das externalidades. ${ }^{56}$ Pense-se em uma situação contemporânea envolvendo o Brasil. Dada a proximidade geográfica entre Brasil e Haiti, caso as condições dos direitos humanos no Haiti atinjam níveis muito baixos, parte da população local poderia emigrar e vir para o Brasil - como de fato está ocorrendo -, trazendo efeitos (positivo e negativos) no país. ${ }^{57}$ Esse fluxo poderia desencadear, em um primeiro momento, uma ação cooperativa de recepção desses imigrantes e, em se alterando a percepção dos benefícios, ações tendentes a controlá-lo ou mesmo cessá-lo. Não deve ser uma surpresa que essa mesma linha de raciocínio, seguindo uma perspectiva racional, seja utilizada na atual crise imigratória envolvendo a Europa e os imigrantes das regiões africanas e do oriente médio.

$55{ }^{57}$ GOLDSMITH, Jack L.; POSNER, Eric A. The limits of international law. Oxford: OUP, 2005. p. 128.

$56{ }^{58}$ Para uma análise detalhada do uso do conceito de racionalidade no campo dos direitos humanos, bem como sua crítica, ver MCGREAL, Daragh. Essays on the law and economics of international buman rights law. Hamburgo: Staats- und Universitätsbibliothek Hamburg, 2013.

$57{ }^{59}$ Alguns alegariam que o motivo do Estado brasileiro se interessar pelas péssimas condições da população da República do Haiti seria meramente altruístico. Para outros, uma forma de ganho reputacional visando fazer parte do seleto grupo de países pertencentes ao membros permanentes do Conselho de Segurança da ONU. Não se afirma neste artigo que a emigração traria prejuízos ao Estado brasileiro. Certamente, uma complexa análise de custos e benefícios poderia apontar quais grupos sociais se beneficiam e se prejudicam pela entrada de mão-de-obra, efeitos na seguridade social, entre outros efeitos. 
Por mais polêmicas que sejam, aqui apenas se quer reforçar o argumento das externalidades como possível fundamento para explicar a ação racional de estados ao regular os direitos humanos. Assumindo-se a escassez de recursos, serve também como um alerta para as possíveis consequências dos cursos racionais das condutas dos Estados.

\subsection{Outras aplicações}

Como se vê, o menu da AEDIP é vasto e oferece um horizonte a mais, sendo aplicado a diversos campos do direito internacional. Tanto em sua parte geral, como em áreas de direito material.

Há trabalhos que discutem a formação e o papel de Organizações Internacionais, ${ }^{58} \mathrm{o}$ papel do soft law, ${ }^{59}$ a fragmentação do direito internacional, ${ }^{60}$ a possibilidade e aplicações de um direito internacional da concorrência, ${ }^{61}$ desenvolvimento econômico e propriedade intelectual, ${ }^{62}$ entre outros.

Este artigo apenas sinalizou alguma destas abordagens e de que forma o método pode contribuir nesse debate.

\section{Considerações finais}

Como introduzido, a academia brasileira de DIP ainda está em um estágio modesto em relação à AEDIP.

$58{ }^{60}$ DUNOFF, Joel L.; TRACHTMAN, Jeffrey P. Economic analysis of international law. Yale Journal of International Law, v. 24, n. 1, p. 1-59, winter 1999. TRACHTMAN, Joel P. The economic structure of international law. Cambridge: HUP, 2008. GUZMAN, A. International organizations and the Frankenstein problem. European Journal of International Law, v. 24, n. 4, 2013, p. 999-1025.

$59{ }^{61}$ VOIGT, Satefan. The economics of informal international law: an empirical assessment. In: PAUWELY, Joost; WOUTERS, Ramses A. (Ed.). Informal international lawmaking. Oxford: Oxford University, 2012. p. 81-105.

$60{ }^{62}$ VAN AAKEN, Anne. Defragmentation of public international law through interpretation: a methodological proposal. Indiana Journal of Global Legal Studies, v. 16, n. 2, p. 483-512, 2009. p. 483-512. RIBEIRO, Gustavo Ferreira. The legality of trade sanctions based on human rights violations: an analysis through law and economics. Economic Analysis of Law Review, v. 3, n. 2, p. 260-281, Dez. 2012.

$61{ }^{63}$ GUZMAN, Andrew T. Antitrust and international regulatory federalism. New York University Law Review, v. 76, p. 1142-1163, Oct. 2001. GUZMAN, Andrew T. Is international antitrust possible? New York University Law Review, v. 73, p. 1501-1548, Nov. 1998. p. 15011548.

$62{ }^{64}$ COOTER, Robert D; SCHAEFER, Hans-Bernd. Solomon's knot: how law can end the poverty of nations. Princeton: PUP, 2011.
Há um baixo número de publicações, grupos de pesquisa e o ensino do método é praticamente ignorado nas instituições de ensino superior brasileiras.

Há uma questão prévia, não desenvolvida no artigo, mas salutar de ser tocada. Deve-se reconhecer que o ensino do direito no Brasil - consideração essa ampla, não apenas ao campo do DIP - é marcada, no bacharelado, predominantemente, pela memorização. Isso é parcialmente um reflexo de um mecanismo de reprodução: os professores tendem a repetir os métodos de aprendizagem aos quais foram expostos. ${ }^{63}$ A resultante é uma estrutura de incentivos perversa com pouco espaço para métodos como a AEDIP.

A discussão se a AEDIP é um método ou não já se encontra praticamente superada. Tanto a academia norte-americana quanto a europeia tomam o método como existente. A primeira de uma forma pragmática, uma vez que a inter-relação das ciências sociais com o direito já ocorre há mais tempo. A última com mais precaução, principalmente, quanto a uma maior reserva do papel do jurista à abordagem hermenêutica, porém com menos resistência ao uso positivo e normativo da AEDIP.

Parece, entretanto, desafiador, mas superável, o problema de linguagem. A construção de uma ponte que possa transmitir ao jurista o vocabulário e o modo de pensar do economista deve ser feita, incluindo boas noções de escassez, racionalidade, maximização, eficiência (Pareto, Kaldor-Hicks), quebras eficientes de contratos, externalidades, análise de custos e benefícios, custos de transação, noções sobre teoria dos jogos, em uma lista que poderia ser aumentada. O mesmo devendo ser dito ao economista que pretenda se aproximar do vocabulário jurídico, dos valores axiológicos do direito e do modus operandi do jurista.

Nesse artigo, procurou-se refletir sobre esse exercício apontando caminhos para se pensar as possibilidades da AEDIP na análise das fontes do direito internacional (tratados e costumes), assim como no seu aproveitamento a campos temáticos (direito internacional dos investimentos e direitos humanos).

63 Existem razões associadas à proliferação de instituições, exames de ordem, concursos públicos que informam esta constatação. MARINHO, Maria Edelvacy Pinto; RIBEIRO, Gustavo Ferreira. Aplicação do método de role-playing em problemas interdisciplinares: direito e economia. In: MEZZAROBA, Orides; TAVARES NETO, José Querino; VASCONCELOS, Silvia Andréia (Orgs.). Direito, educação, ensino e metodologia jurídicos. Florianópolis: FUNJAB, 2013. p. 360-374. 
Dada a massa crítica de estudantes e pesquisadores já ocupados com a análise econômica do direito, com temas de relações internacionais, e de direito internacional, e a variedade de instituições brasileiras que possuem cursos nessas áreas, pode haver um ambiente favorável ao desenvolvimento dessa nova abordagem nos próximos anos. Pesquisadores e estudantes interessados no tema, entretanto, carecem de mais publicações, inclusive de manuais em português sobre a disciplina e sobre o estado da pesquisa internacional. A falta de um ou mais grupos de pesquisa de análise econômica do direito internacional também chama a atenção e começa a ser remediada. Isso poderia, sem dúvida, ajudar a estreitar os laços acadêmicos do Brasil com instituições estrangeiras e pesquisadores que já se ocupam do tema. Poderia, também, ajudar a definir uma agenda nacional de pesquisa que inclua temas de interesse do Brasil e dos brasileiros.

Isso resultaria em uma aproximação mais significativa com centros de vanguarda no campo do DIP que passam, cada vez mais, a se comunicar por meio desse método e linguagem.

\section{REFERÊNCIAS}

BELONIEL, Daniel; SALAMA, Bruno. Towards an intellectual property bargaining theory: the post-wto era. University of Pennsylvania Journal or International Law, v. 32, n. 1, p. 265-368, 2010.

BHANDARI, Jagdeep S.; SYKES, Alan O. (Org.). Economic dimensions in international law comparative and empirical perspectives. Cambridge: CUP, 1998.

BLAUG, M. The methodology of economics: or how economists explain. 2. ed. Cambridge: CUP, 1992.

BROUDE, Tomer. Behavioral international law. Hebrew University of Jerusalem International Law Forum Research Paper, n. 12-13, p. 1-85, 2013. doi: 10.2139/ssrn.2320375.

CAIADO, José Guilherme Moreno. From coordination to collaboration: explaining international disputes over tariff classification. Economic Analysis of Law Review, v. 3, n. 1, p. 95-108, Jun. 2012.

CALABRESI, Guido; MELAMED, A. Douglas. Property rules, liability rules, and inalienability: one view of the cathedral. Harvard Law Review, v. 85, n. 6, p. 10891128, Abr. 1972.
CARREAU, Dominique; FLORY, Thiébault; JULLIARD, Patrick. Droit internacional èconomique. Paris: Persée, 1990.

CHARNOVITZ, Steve. What is international economic law? Journal of International Economic Law, v. 14, n. 1, p. 3-22, 2014.

COOTER, Robert D.; SCHAEFER, Hans-Bernd. Solomon's knot: how law can end the poverty of nations. Princeton: PUP, 2011.

COOTER, Robert; ULEN, Thomas. Direito e economia. 5. ed. Porto Alegre: Bookman, 2010.

DUNOFF, Joel L.; TRACHTMAN, Jeffrey P. Economic analysis of international law. Yale Journal of International Law, v. 24, n. 1, p. 1-59, winter 1999.

ELTZ, Magnum Koury de Figueiredo. Uma abordagem da análise econômica do direito para os danos ambientais transfronteiriços. Economic Analysis of Law Review, v. 3, n. 1, p. 40-56, Jun. 2012.

GOLDSMITH, Jack L.; POSNER, Eric A. A theory of customary international law. University of Chicago Law Review, Chicago, v. 66, p. 1133-1177, 1999.

GOLDSMITH, Jack L.; POSNER, Eric A. The limits of international law. Oxford: OUP, 2005.

GUZMAN, Andrew T. Antitrust and international regulatory federalism. New York University Law Review, v. 76, p. 1142-1163, Oct. 2001.

GUZMAN, Andrew T. How international law works. Oxford: OUP, 2008.

GUZMAN, Andrew T. Is international antitrust possible? New York University Law Review, v. 73, p. 1501-1548, Nov. 1998.

GUZMAN, Andrew. International organizations and the Frankenstein problem. European Journal of International Law, v. 24, n. 4, p. 999-1025, 2013.

HAFNER-BURTON, Emilie M.; LEVECK, Brad L.; VICTOR, David G. Strategic enforcement: results from an elite survey experiment on international trade agreements. SSRN Electronic Journal, Aug. 2012. doi: 10.2139/ ssrn.2132948. Available at: <https://www.researchgate. net/publication/256031577_Strategic_Enforcement_ Results_from_an_Elite_Survey_Experiment_on_International_Trade_Agreements $>$. Access: Feb. 09, 2016. 
HOLMES, Stephen; SUNSTEIN, Cass R. The cost of rights: why liberty depends on taxes. New York: WW Norton, 1999.

LUPI, André Lipp Pinto Basto. Os métodos no direito internacional. São Paulo: Lex, 2007.

MARINHO, Maria Edelvacy Pinto; RIBEIRO, Gustavo Ferreira. Aplicação do método de role-playing em problemas interdisciplinares: direito e economia. In: MEZZAROBA, Orides; TAVARES NETO, José Querino; VASCONCELOS, Silvia Andréia (Orgs.). Direito, educaşão, ensino e metodologia jurídicos. Florianópolis: FUNJAB, 2013. p. 360-374.

MCGREAL, Daragh. Essays on the law and economics of international human rights law. Hamburgo: Staats- und Universitätsbibliothek Hamburg, 2013.

MONTILLA FERNÁNDEZ, Luis Tomás. Land policies and labour markets in Sub-Saharan Africa: a law and economics analysis. IDS Bulletin, v. 43, n. 6, p. 78-89, 2012. doi: 10.1111/j.1759-5436.2012.00381.x.

NOGUEIRA, João Pontes; MESSARI, Nizar. Teoria das relações internacionais. São Paulo: Elsevier, 2005.

OETER, Stefan. Legitimacy of customary international law. In: EGER, Thomas; OETER, Stefan; VOIGT, Stefan (Ed.). Economic analysis of international law: contributions to the XIIIth Travemünde symposium on the economic analysis of law (March 29-31, 2012). Tübingen: Mohr Siebeck, 2012. p. 1-22.

PAUWELYN, Joost. Optimal protection of international law: navigating between european absolutism and american voluntarism. Cambridge: CUP, 2008.

PINDYCK, Robert S.; RUBINFELD, Daniel L. Microeconomia. 7. ed. São Paulo: Pearson, 2010.

POSNER, Eric A. Human welfare, not human rights. Columbia Law Review, v. 108, p. 1758-1802, 2008.

POSNER, Eric A.; SYKES, Alan O. Economic foundations of international law. Cambridge: HUP, 2013.

RATNER, Steven R.; SLAUGHTER, Anne Marie. Appraising the methods of international law: a prospectus for readers. American Journal of International Law, v. 93, n. 2, p. 291-302, April 1999.

RIBEIRO, Gustavo Ferreira. The legality of trade sanctions based on human rights violations: an analysis through law and economics. Economic Analysis of Law
Review, v. 3, n. 2, p. 260-281, Dez. 2012.

RIBEIRO, Gustavo Ferreira; GICO JR, Ivo T. (Org.). O jurista que calculava. Curitiba: CRV, 2013.

RUGGIE, John Gerard; BURLEY, Anne-Marie (Ed.). Multilateralism matters: the theory and praxis of an institutional form. New York: Columbia Universtity, 1993.

SALAMA, Bruno Meyerhof (Org.). Direito e economia: textos escolhidos. São Paulo: Saraiva, 2010. (Direito em Debate).

SANTOS, Alexandre Leite. O direito internacional público como jogo institucional. Economic Analysis of Law Review, v. 1, n. 2, p. 179-195, July/Dez. 2010.

SASSE, Jan Peter. An economic analysis of bilateral investment treaties. Hamburgo: Gabler, 2011.

SCHROPP, Simon. A. B. Trade policy flexibility and enforcement in WTO: a law and economics analysis. Cambridge: CUP, 2009.

SEN, Amartya. On ethics and economics. Malden: Blackwell, 1987.

SOARES, Guido Fernando Silva. Curso de direito internacional público. 2. ed. São Paulo: Atlas, 2004. v. 1.

SORNARAJAH, M. The international law of foreign investment. 3. ed. Cambridge: CUP, 2010.

SYKES, Alan O. Protectionism as a "safeguard": a positive analysis of the gatt "escape clause" with normative speculations. University of Chicago Law Review, v. 58, n. 1, p. 255-306. winter 1991.

TIMM, Luciano (Org.). Direito e economia no Brasil. 2. ed. São Paulo: Atlas, 2014.

TIMM, Luciano (Org.). Direito e economia. Porto Alegre: Livraria do Advogado, 2008.

TRACHTMAN, Joel P. The economic structure of international law. Cambridge: HUP, 2008.

TRACHTMAN, Joel P. The future of international law: global government. Cambridge: CUP, 2013.

UNITED NATIONS CONFERENCE ON TRADE AND DEVELOPMENT. International Investment Agreements Navigator. Available at: <http://investmentpolicyhub.unctad.org/IIA>. Access: Out. 15, 2015.

VAN AAKEN, Anne. Behavioural international law and economics. Harvard International Law Journal, n. 55, 
p. 421-481, summer 2014.

VAN AAKEN, Anne. Defragmentation of public international law through interpretation: a methodological proposal. Indiana Journal of Global Legal Studies, v. 16, n. 2, p. 483-512, 2009.

VAN AAKEN, Anne. International investment law between commitment and flexibility: a contract theory analysis. Journal of International Economic Law, v. 12, n. 2, p. 507-538, 2009.

VAN AAKEN, Anne. Opportunities for and limits to an economic analysis of international economic law. Law and Economics Research Paper Series, v. 9, n. 31, 2010.

VAN AAKEN, Anne. Smart flexibility clauses in international investment treaties and sustainable development: a functional view. Journal for World Investment and Trade, v. 15, n. 5-6, p. 827-861, 2014.

VOIGT, Satefan. The economics of informal international law: an empirical assessment. In: PAUWELY, Joost; WOUTERS, Ramses A. (Ed.). Informal international lawmaking. Oxford: Oxford University, 2012. p. 81-105. 
Para publicar na Revista de Direito Internacional, acesse o endereço eletrônico www.rdi.uniceub.br ou www.brazilianjournal.org.

Observe as normas de publicação, para facilitar e agilizar o trabalho de edição. 